\title{
RETRACTED ARTICLE: The complete nucleotide sequences of serotype ' $O$ ' and ' $A$ ' Indian vaccine strains of foot-and-mouth disease virus
}

Madala Uma $\cdot$ P. Panduranga Rao $\cdot$

Meena Keerti $\cdot$ Sree Narayan Singh ·

Nagendra R. Hegde

Received: 11 April 2011/Accepted: 6 July 2011/Published online: 22 July 2011

(C) Springer-Verlag 2011

Authors wish to withdraw the paper due to their conflict of interest with a third party.

M. Uma · P. P. Rao $(\bowtie) \cdot$ M. Keerti · N. R. Hegde

Ella Foundation, Genome Valley, Turkapally, Shameerpet

Mandal, Hyderabad 500078, India

e-mail: raopp@ellafoundation.org

S. N. Singh

Biovet Private Limited, Plot No. 308, KIADB Industrial Area

Phase III, Malur, Kolar District 563130, Karnataka, India 